\title{
Sex differences among Swedish adolescents in mother-child relationships in the intake of different food groups
}

\author{
Karin Vågstrand* \\ Obesity Unit, M73, Department of Medicine Huddinge, Karolinska Institutet, Karolinska University Hospital Huddinge, \\ 14186 Stockholm, Sweden \\ (Received 23 May 2009 - Revised 17 September 2009 - Accepted 21 October 2009 - First published online 25 January 2010)
}

The present study has explored mother-child relationships in the intake of different food groups and the sex differences in these relationships. A population-based sample of 471 mother-child pairs from Stockholm completed a dietary questionnaire to assess habitual dietary intake. Girls showed overall stronger correlations with their mothers' diet than boys did. The strongest correlations found, in both girls and boys, were for the intakes of fruit juice and sweet bakery goods $(r 0.30-0 \cdot 37, P<0 \cdot 001)$. There was a wide range in correlation strength between food groups. Milk/yoghurt and desserts showed no mother-child relationship at all. Breakfast cereals was the only food group with a significant sex interaction $(P=0.01$; mothers-girls, $r 0.30, P<0.001$; mothers-boys, $r 0.05$, NS). There were significant positive correlations between mothers and daughters in the intake of all macronutrients, whereas none between mothers and sons (sex interactions: protein, $P=0 \cdot 001 ;$ fat, $P=0 \cdot 004$ carbohydrates, $P=0.001)$. Mothers and daughters $(r 0.29, P<0.001)$, but not mothers and sons, showed significant correlation in total energy intake, $(P=0.001$ for sex interaction). There were generally more differences between mothers and children than between boys and girls in the relative intake (percentage of energy) of different food groups. Since teenaged children have a similar intake of especially snack foods as their mothers, it could be meaningful to educate mothers when aiming at improving the diet of teenaged children, both boys and girls.

Diet: Mother-child relationships: Sex differences: Adolescents: Food groups

One of the greatest threats to public health today is obesity and of special concern is the development of overweight in children and adolescents. The prevalence of overweight and obesity has increased in the last few decades in Sweden ${ }^{(1)}$ as well as in most other countries ${ }^{(2)}$. In that light, to study the diet of children and adolescents is most crucial. The aetiology of obesity is very complex involving many factors, and we have to explore all of these factors to increase our knowledge of how eating habits in children evolve. In the present paper, we are focusing on the relationships between mother and teenaged children in the intake of different food groups.

We know that parents have an important influence on dietary behaviours of the child, through shared genes as well as through shared environment ${ }^{(3,4)}$, and it is well known that obesity and overweight run in families ${ }^{(5)}$. Mothers, as well as fathers, have obviously both positive and negative influences on their children's eating habits. It has been shown that children of obese mothers have a higher intake of dietary fat than other children ${ }^{(6,7)}$, and that daughters of mothers who consume a greater amount of fruits and vegetables eat more fruits and vegetables than other girls ${ }^{(8)}$. Sharing meals with the family seems to protect against overweight ${ }^{(9,10)}$, but at the same time, problematic eating behaviours such as bulimic behaviour and emotional eating have been linked between mothers and daughters as well as between fathers and sons ${ }^{(11,12)}$.
In the present study, we have compared the diet of mothers with the diet of their teenaged children. Adolescence is typically a time of gradual shift from parental to peer influence and it is likely that the older the child, the less that eating habits are shared with their parents ${ }^{(13,14)}$. However, the evidence is inconclusive, since some studies have shown that age is unrelated to the level of parental impact ${ }^{(13,15)}$.

Most previous studies have restricted their focus to the nutrient intake rather than the intake of different food items ${ }^{(13,16,17)}$. The diet, and the predictors of certain food choices, is very complex and it is important to study the diet from many different angles. Therefore, studying the intake of different food groups is a good complement to existing data of nutrient intake.

The aim of the present study was to explore mother-child relationships in the intake of different food groups, and, in addition, to study the sex differences in these relationships.

\section{Methods}

Subjects

Subjects were participants in the Stockholm Weight Development Study (SWEDES) ${ }^{(18)}$. The recruitment base was 2342 participants from a pregnancy study, Stockholm Pregnancy

Abbreviations: EE, energy expenditure; EI, energy intake; SWEDES, Stockholm Weight Development Study.

* Corresponding author: Dr Karin Vågstrand, fax +46 877499 62, email karin.vagstrand@ki.se 
and Weight Development Study, from $1984^{(19)}$, which represented a cross-sectional sample of women of southern Stockholm. Of these women, 1906 mothers were invited in 2001-2 and $25 \%$ of those $(n$ 481) agreed to participate together with their children in SWEDES. Mothers who had moved away from the Stockholm area were not contacted. Drop-out analyses of data from Stockholm Pregnancy and Weight Development Study showed that the mothers participating in SWEDES were not different than non-participators in aspects of eating habits related to pregnancy and body measurements ${ }^{(18)}$. However, there were differences in social parameters. The SWEDES population had a higher education level than expected with over $60 \%$ of the mothers being highly educated compared with about $25 \%$ in the general population $^{(20)}$.

Mothers and children spent half a day in a hospital clinic together filling in questionnaires and undergoing measurements, equal for mother and child, some used in this sub-study. Seven children (four girls, three boys) and two mothers did not complete the dietary questionnaire, either due to lack of understanding or to simple refusal and therefore not included in the present study. One additional girl was excluded due to pregnancy, leaving 471 mother-child pairs to be included in the present study. See Table 1 for subject characteristics. All results in the present paper are based on the cross-sectional study of SWEDES from 2001-2.

\section{Dietary intake}

A dietary questionnaire originally developed for the Swedish Obese Subjects study was used to assess the dietary intake $^{(21)}$. The children filled in the questionnaire on their own with the mothers beside them. In a previous validation study, mean energy intake (EI) from the questionnaire did not differ significantly from estimated energy expenditure (EE) in neither normal-weight nor obese adults ${ }^{(21)}$. The questionnaire has also previously been validated in eighteen 15 -year-old adolescents (50\% boys) with the doubly labelled water method ${ }^{(22)}$, where the reported mean EI did not differ significantly from measured EE.

The questionnaire is based on a simplified dietary history. It is supposed to cover the total dietary intake during the past 3 months. The eaten foods were classified into sixteen different foods groups, whereof twelve are presented in the results of the present paper. Food groups not presented individually are light meals (soups, salads etc) miscellaneous (egg and sandwich toppings without bread) and other beverages (chocolate drinks, coffee, tea and alcoholic beverages). These foods are, however, included in the total EI. Emphasis in the questionnaire is placed on cooked meals (meat/fish + potatoes/pasta/rice + vegetables) and sandwiches. The questionnaire includes three coloured photographs with different amounts on the plates to assist the subjects in describing portion sizes of the cooked meals. The amounts of cooked meals were given separately for Monday-Thursday, Friday and Saturday/Sunday. The definition of sandwiches was all kinds of bread (toast, hard bread, rolls etc) with some kind of topping (cheese, ham, butter, spreads etc.). The bread type, thickness and contents were quantified in detail.

Sweets (candies and chocolates) and cakes etc. (sweet bakery goods such as cakes, pastries, cookies and biscuits)

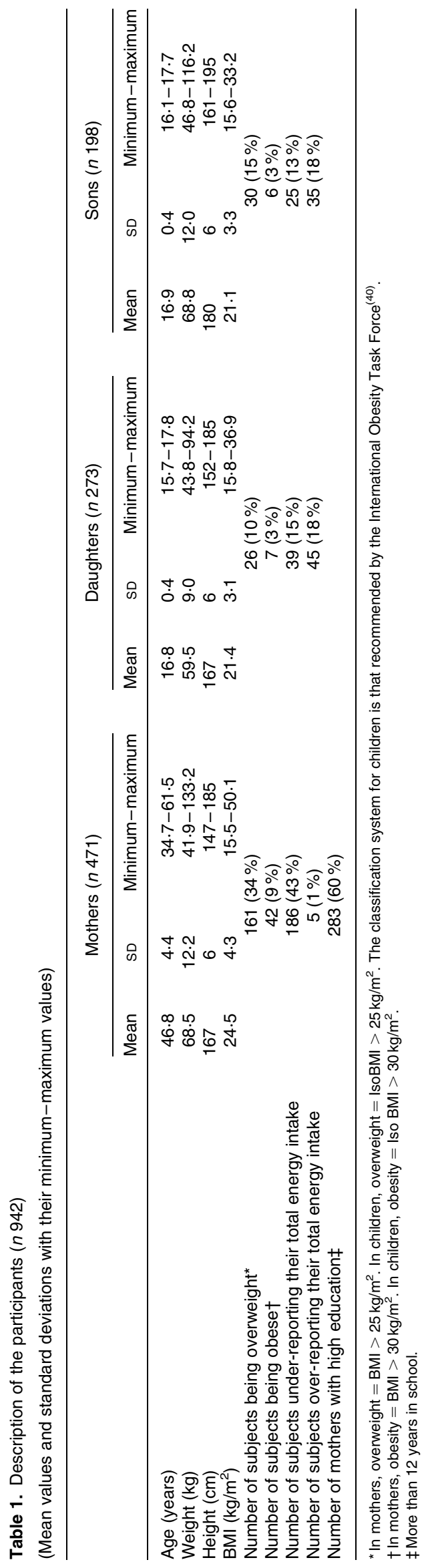


were quantified based on the sizes of packages sold in Sweden or per units of $100 \mathrm{~g}$. Salty snacks (crisps and cheese doodles) were also quantified by package size, and soft drinks, fruit juice and milk and yoghurts by pre-defined portion sizes. The fast food variable consists of pizzas, hot dogs and hamburgers. The amounts of all reported foods were converted into EI and nutrient intake per day, using food tables from the Swedish National Food Administration ${ }^{(23)}$. Sugars are defined in the present paper as all mono- and disaccharides.

For identifying under- and over-reporting, reported EI was compared with the EE. EE was calculated by adding the results of a physical activity questionnaire, Swedish adolescent physical activity questionnaire (SAPAQ) ${ }^{(24)}$ for the children and international physical activity questionnaire (IPAQ) ${ }^{(25)}$ for the mothers, to the calculated $\mathrm{BMR}^{(26)}$. Several CI for EI:EE were constructed, with different intervals depending on the level of physical activity, wherein an individual had to be considered to be an adequate reporter of EI. For more details of the classification into misreporting groups, please see Vågstrand et al. ${ }^{(27)}$.

\section{Other measurements}

Weight and height, for the calculation of BMI, were measured at the clinic. Weight was measured to the nearest $0.1 \mathrm{~kg}$ with subjects standing dressed in underwear. Standing height was measured to the nearest $1.0 \mathrm{~cm}$.

Educational level of the mother was assessed by a multiple choice question. The answers were collapsed into two alternatives: high education (more than 12 years in school/college/ university) or low education (12 years or less).

\section{Statistics}

All statistical analyses were performed in SPSS (version 15.0; SPSS Inc., Chicago, IL USA). Most dietary variables had skewed distribution and are therefore presented as median and range in Table 2. Consequently, the analyses of these results were done with non-parametric tests (Mann-Whitney $U$ test). To meet the normal distribution assumption of the parametric tests (Pearson correlation analysis and linear regression analyses), skewed variables were logarithmic transformed before analysed. To calculate interactions between boys and girls, linear regression analyses were performed including an interaction variable (variable $\times$ sex). A $P$-level below 0.05 was considered statistically significant.

There is always a choice between using crude data and adjusting the intake to total EI. Energy adjustment is, however, debated ${ }^{(28)}$, and there is a risk that the magnitude of selective misreporting increases in energy-adjusted models. Nevertheless, to be sure not to miss any information, we have repeated all correlation analyses using either energy percentage or energy-adjusted ${ }^{(29)}$ variables of all nutrients and food groups. The results of these analyses showed quite similar results to the ones presented here.

The present study was conducted according to the guidelines laid down in the Declaration of Helsinki and all procedures involving human subjects/patients were approved by the local Ethics committee of Huddinge University Hospital. Written informed consent was obtained from all the mother-child pairs.

\section{Results}

Table 2 shows the intake of macronutrients and the EI from different food groups in mothers, daughters and sons. Boys had a larger absolute intake of all nutrients and food groups, except breakfast cereals and fruit, than both mothers and girls. The relative intake (percentage of energy), however, differed in most variables, with more differences between mothers and children than between boys and girls. The relative intake of protein and salty snacks were the only variables with similar intake in all the three groups.

All macronutrients were significant positively correlated between mothers and daughters, whereas none was correlated between mothers and sons (Fig. 1). All macronutrients, but fibre, showed significant sex interaction (protein, $P=0.001$; fat, $P=0.004$; carbohydrates, $P=0.001$; sugars, $P=0.002$ ). The associations in total EI showed similar results; mothers and daughters had a significant and relatively strong correlation $(r 0 \cdot 29, P<0 \cdot 001)$, whereas mothers and sons showed no association in EI at all $(r-0.04, P=0.6 ; P=0.001$ for sex interaction).

There were significant associations between mothers and sons in the intake of many food groups, but the overall result was that mothers and girls were more strongly correlated in their intakes than mothers and sons were (Fig. 2). The strongest correlations found, in both girls and boys, were the intakes of fruit juice and cakes, whereas the intake of milk/yoghurt and of desserts showed no correlation.

Beside the sex difference in correlation strength, there were also differences in which food groups related to the mother. The most obvious example was the intake of breakfast cereals and cooked meals, where boys had no resemblance at all with their mothers. Breakfast cereals was the only food group with significant sex interaction $(P=0 \cdot 01)$.

In Table 3 , the results of multiple regression analyses are presented for boys and girls together, adjusted for education, age and BMI of mother, and sex and BMI of child. Protein and fat had no significant association between mother and child in this analysis, whereas carbohydrates and fibre did. Fruit juice, cakes etc, salty snacks and fruit were the food groups with the strongest association in this analysis in concordance with the unadjusted correlations.

The BMI of both girls and boys had a significant positive and equally strong correlation with the BMI of mothers, $r 0.19(P=0.001)$ for girls and $r 0.21(P=0.003)$ for boys. However, when physical activity was adjusted for, the BMI correlation in boys was no longer significant, $r 0 \cdot 13$, whereas unchanged in girls, $r 0 \cdot 20, P=0 \cdot 002$.

\section{Discussion}

In the present paper, we have shown three things: (1) girls had overall stronger correlations with their mothers' dietary intake than boys had, especially in the intake of macronutrients. (2) There were large differences in correlation between different food groups. The intake of some food groups (for example fruit juice, cakes and salty snacks) had strong correlations in both the sexes, whereas other showed no relationship at all (milk and desserts). (3) Different food groups showed correlations in girls than in boys. The intakes of cooked meals 
Table 2. Dietary intake of mothers, daughters and sons ( $n$ 942)

(Median and minimum-maximum values)

\begin{tabular}{|c|c|c|c|c|c|c|}
\hline & \multicolumn{2}{|c|}{ Mothers ( $n$ 471) } & \multicolumn{2}{|c|}{ Daughters ( $n$ 273) } & \multicolumn{2}{|c|}{ Sons (n 198) } \\
\hline & Median & Minimum-maximum & Median & Minimum-maximum & Median & Minimum-maximum \\
\hline \multicolumn{7}{|c|}{ Total energy } \\
\hline MJ & $8 \cdot 0^{*} \dagger$ & $3 \cdot 8-16 \cdot 9$ & $9 \cdot 4 \dagger$ & $3.0-36.9$ & $13 \cdot 5$ & $5 \cdot 7-44 \cdot 0$ \\
\hline kcal & 1910 & & 2240 & & 3220 & \\
\hline \multicolumn{7}{|l|}{ Protein } \\
\hline g & $80^{*} \dagger$ & $40-190$ & $90 \dagger$ & $30-300$ & 130 & $50-340$ \\
\hline $\mathrm{E} \%$ & 16 & $11-23$ & 16 & $7-23$ & 17 & $9-26$ \\
\hline \multicolumn{7}{|l|}{ Fat } \\
\hline g & $70^{*} \dagger$ & $30-160$ & $90 \dagger$ & $20-350$ & 130 & $60-440$ \\
\hline $\mathrm{E} \%$ & $33^{*} \dagger$ & $17-50$ & $34 \dagger$ & $14-45$ & 37 & $24-47$ \\
\hline \multicolumn{7}{|c|}{ All carbohydrates } \\
\hline $\mathrm{g}$ & $220^{*} \dagger$ & $100-520$ & $280 \dagger$ & $80-1120$ & 370 & $150-1320$ \\
\hline $\mathrm{E} \%$ & $47^{*}$ & $27-65$ & $49 \dagger$ & $36-78$ & 47 & $32-67$ \\
\hline \multicolumn{7}{|c|}{ Sugarsł } \\
\hline $\mathrm{g}$ & $80^{*} \dagger$ & $20-330$ & $130 \dagger$ & $40-560$ & 160 & $60-740$ \\
\hline $\mathrm{E} \%$ & $19^{\star} \dagger$ & $6-42$ & $22 \dagger$ & $10-47$ & 21 & $8-36$ \\
\hline \multicolumn{7}{|l|}{ Fibre } \\
\hline $\mathrm{g}$ & $20 \dagger$ & $10-50$ & $20 \dagger$ & $0-70$ & 20 & $10-80$ \\
\hline $\mathrm{g} / \mathrm{MJ}$ & $2^{*} \dagger$ & $1-5$ & $2 \dagger$ & $0-5$ & 2 & $1-3$ \\
\hline \multicolumn{7}{|c|}{ Cooked meals } \\
\hline $\mathrm{kJ}$ & $1980^{*} \dagger$ & $0-7150$ & $2370 \dagger$ & $200-12160$ & 3510 & $920-13330$ \\
\hline$E \%$ & 25 & $0-61$ & $25 \dagger$ & $3-52$ & 27 & $4-64$ \\
\hline \multicolumn{7}{|c|}{ Fast food } \\
\hline $\mathrm{kJ}$ & $330^{*} \dagger$ & $0-2050$ & $330 \dagger$ & $0-4430$ & 650 & $0-3360$ \\
\hline $\mathrm{E} \%$ & $3^{*} \dagger$ & $0-16$ & 4 & $0-27$ & 5 & $0-26$ \\
\hline \multicolumn{7}{|c|}{ Sandwiches } \\
\hline kJ & $1490 \dagger$ & $0-6700$ & $1540 \dagger$ & $0-7310$ & 2230 & $0-10790$ \\
\hline$E \%$ & $20^{*} \dagger$ & $0-56$ & 17 & $0-42$ & 17 & $0-50$ \\
\hline \multicolumn{7}{|c|}{ Breakfast cereals } \\
\hline $\mathrm{kJ}$ & $160^{*}$ & $0-4580$ & 100 & $0-1490$ & 130 & $0-2480$ \\
\hline$E \%$ & $2^{*} \dagger$ & $0-38$ & 1 & $0-17$ & 1 & $0-10$ \\
\hline \multicolumn{7}{|c|}{ Milk and yoghurt } \\
\hline $\mathrm{kJ}$ & $510^{*} \dagger$ & $0-5200$ & $1030 \dagger$ & $0-8880$ & 1680 & $0-8140$ \\
\hline $\mathrm{E} \%$ & $7^{*} \dagger$ & $0-32$ & 11 & $0-51$ & 12 & $0-38$ \\
\hline \multicolumn{7}{|l|}{ Fruit } \\
\hline $\mathrm{kJ}$ & $520^{*} \dagger$ & $0-3010$ & 350 & $0-2380$ & 310 & $0-2940$ \\
\hline$E \%$ & $7^{*} \dagger$ & $0-32$ & $3 \dagger$ & $0-24$ & 2 & $0-14$ \\
\hline \multicolumn{7}{|c|}{ Fruit juice } \\
\hline $\mathrm{kJ}$ & $110^{*} \dagger$ & $0-2810$ & $230 \dagger$ & $0-3210$ & 400 & $0-2410$ \\
\hline $\mathrm{E} \%$ & $2^{*} \dagger$ & $0-40$ & 2 & $0-34$ & 2 & $0-18$ \\
\hline \multicolumn{7}{|c|}{ Soft drinks } \\
\hline $\mathrm{kJ}$ & $0^{*} \dagger$ & $0-2680$ & $240 \dagger$ & $0-2680$ & 330 & $0-3870$ \\
\hline$E \%$ & $0 * \dagger$ & $0-17$ & $2 \dagger$ & $0-23$ & 3 & $0-20$ \\
\hline \multicolumn{7}{|l|}{ Sweets } \\
\hline kJ & $370^{*} \dagger$ & $0-2590$ & $590 \dagger$ & $0-9800$ & 730 & $0-3630$ \\
\hline$E \%$ & $5^{\star}$ & $0-31$ & 6 & $0-62$ & 5 & $0-29$ \\
\hline Salty sr & & & & & & \\
\hline $\mathrm{kJ}$ & $170^{*} \dagger$ & $0-1900$ & $250 \dagger$ & $0-1690$ & 320 & $0-3170$ \\
\hline $\mathrm{E} \%$ & 2 & $0-18$ & 2 & $0-16$ & 2 & $0-15$ \\
\hline Cakes & & & & & & \\
\hline $\mathrm{kJ}$ & $220 \dagger$ & $0-2290$ & $240 \dagger$ & $0-1850$ & 260 & $0-7330$ \\
\hline$E \%$ & $3^{*} \dagger$ & $0-21$ & 2 & $0-14$ & 2 & $0-17$ \\
\hline Dessert & & & & & & \\
\hline kJ & $90^{*} \dagger$ & $0-1500$ & 190 & $0-1750$ & 230 & $0-4070$ \\
\hline$E \%$ & $1^{*} \dagger$ & $0-12$ & 2 & $0-14$ & 2 & $0-12$ \\
\hline
\end{tabular}

$\mathrm{E} \%$, percent of total energy intake.

* Median values were significantly different from daughters (Mann-Whitney $U$ test).

$\dagger$ Median values were significantly different from sons (Mann-Whitney $U$ test)

‡'Sugars' include all mono- and disaccharides.

and breakfast cereals were correlated in girls, but not in boys, whereas sweets were more strongly correlated in boys.

Previous studies of the association between eating habits of parents and children have presented correlations between $0 \cdot 2$ and 0.5 for both the energy and macronutrient intakes in both boys and girls ${ }^{(13,16,17)}$. Oliveria et al. ${ }^{(17)}$ found stronger correlations between mothers and daughters $(r 0.4-0 \cdot 5)$ than between mothers and sons $(r 0 \cdot 1-0 \cdot 3)$, whereas others presented no obvious sex difference at all ${ }^{(13,16)}$. In the present study, we have found a similar strength of correlation between 

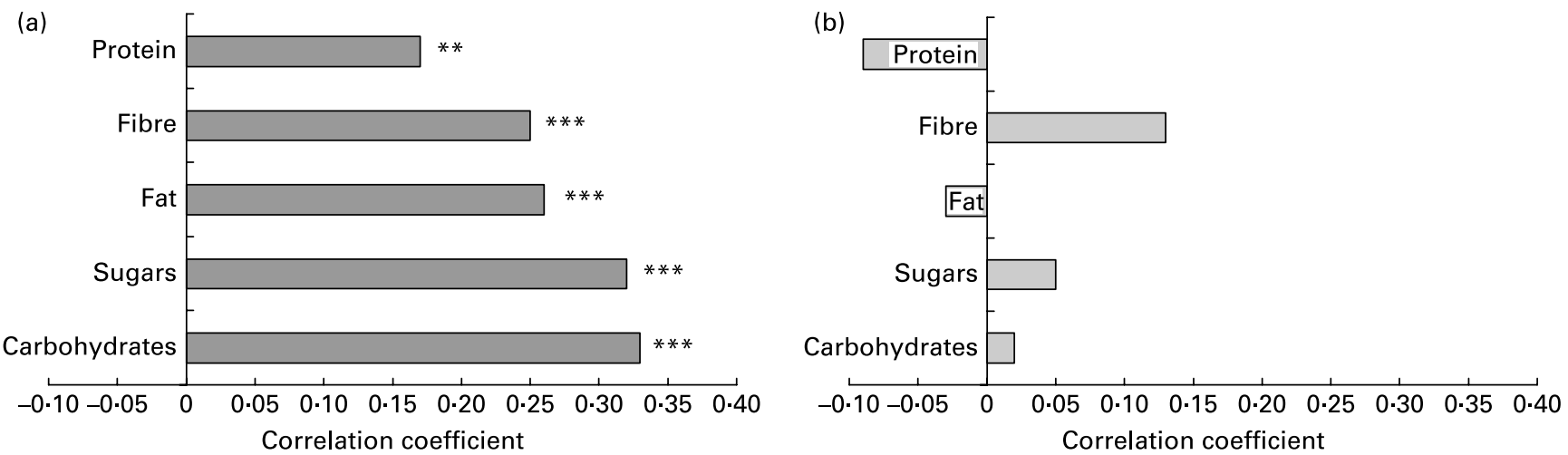

Fig. 1. Pearson's correlations between the energy intake of macronutrients of (a) mothers and daughters and (b) mothers and sons. 'Sugars' include all mono- and

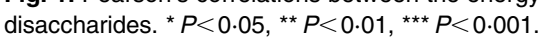

mothers and daughters as in most previous studies but much weaker relationships between mothers and sons. These previous studies had populations of children of mixed ages $^{(13,16)}$ or younger children ${ }^{(17)}$. Not many previous papers have studied the relationship between eating habits of parents and adolescent children exclusively, and more research is needed.

There was a great variability in the mother-child correlation across different food groups, which suggests that more complex processes are at work than simply shared meals, and we can only speculate about why some foods are correlated and others are not. Previous studies have shown a parental-child connection in the intake of fat, vegetables and fruit ${ }^{(30)}$, which is only partially supported by the present study. Vegetables were not calculated separately here but are included in the variable 'cooked meals'.

The overall stronger correlations in girls than in boys found in the present study could simply be a result of the fact that men and women often make different food choices ${ }^{(31)}$. Women report, for example, often higher intakes of fruit and vegetables and lower intakes of fat and are more health conscious than men are. These sex differences in food choices have also been seen among teenagers ${ }^{(32-34)}$. Therefore, it is no surprise that the girls showed stronger correlations with the parent of the same sex (mother) than the boys did. If we had dietary data of the fathers, we would expect that the sons had a closer resemblance to the diet of their fathers.

Some food groups were equally correlated in boys and girls, whereas other correlations were only found among girls. This might be an indication of how males and females have different approaches towards some foods, something that need more research attention. For example, it is possible that boys eat breakfast cereals in a different manner than girls and women do, maybe as snack foods between meals or late at night. We have previously shown that boys report eating late at night at a much greater extent than girls ${ }^{(35)}$, but unfortunately we do not have any information in the present study on when during the day the different foods were consumed.

It is also possible that boys choose more energy-dense food items than girls and mothers do within the same food group, for example, high-fat sandwich spreads instead of low-fat spreads, high-sugar cereals instead of low-sugar cereals, etc. This might contribute to the differences in correlation between boys and girls, even though not explain it entirely.

The number of family meals consumed during a typical week seems to decline with increasing age ${ }^{(14)}$ and Feunekes et al. ${ }^{(13)}$ showed that the correlation for fat intake was much higher for foods eaten within the family than foods

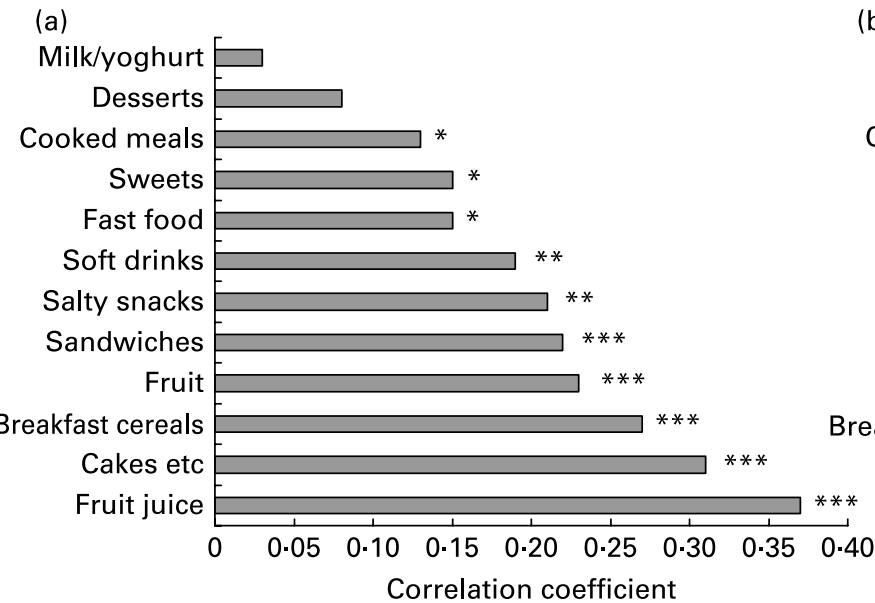

(b)

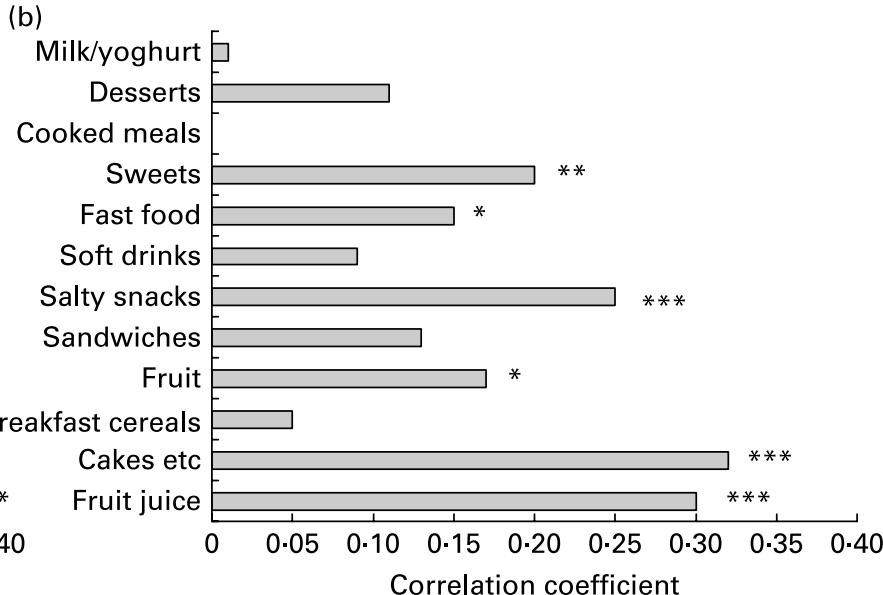

Fig. 2. Pearson's correlations between the energy intake of different food groups of (a) mothers and daughters and (b) mothers and sons. ${ }^{*} P<0.05,{ }^{\star \star} P<0.01$ ${ }^{\star * *} P<0.001$ 
Table 3. Linear regression models with the child intake of either nutrients or food groups as dependent variables, and the mothers' intake as independent variable*

\begin{tabular}{llccc}
\hline Model no. & Tested variable & Standardised $\beta$ & $P$ & Adjusted $R^{2}$ \\
\hline 1 & Total energy & 0.13 & 0.002 & $0.22 \dagger$ \\
2 & Protein & 0.05 & 0.20 & $0.19 \dagger$ \\
3 & Fat & 0.11 & 0.006 & $0.24 \dagger$ \\
4 & All carbohydrates & 0.18 & $<0.001$ & $0.19 \dagger$ \\
5 & Sugars $\ddagger$ & 0.19 & $<0.001$ & $0.14 \dagger$ \\
6 & Fibre & 0.19 & $<0.001$ & $0.07 \dagger$ \\
7 & Fruit juice & 0.33 & $<0.001$ & 0.11 \\
8 & Cakes etc & 0.31 & $<0.001$ & 0.10 \\
9 & Salty snacks & 0.22 & $<0.001$ & 0.07 \\
10 & Fruit & 0.19 & $<0.001$ & 0.04 \\
11 & Sweets & 0.15 & $<0.001$ & 0.04 \\
12 & Sandwiches & 0.17 & $<0.001$ & $0.09 \dagger$ \\
13 & Breakfast cereals & 0.17 & $<0.001$ & 0.03 \\
14 & Fast food & 0.15 & 0.001 & 0.04 \\
15 & Soft drinks & 0.12 & 0.005 & $0.13 \dagger$ \\
16 & Dessert & 0.11 & 0.02 & 0.03 \\
17 & Cooked meals & 0.07 & 0.10 & $0.18 \dagger$ \\
18 & Milk & 0.02 & 0.68 & $0.07 \dagger$ \\
& & & &
\end{tabular}

* The models are adjusted for sex of child, age of mother, educational level of mother and BMI of both child and mother.

†The sex variable has a $P$-value $<0.001$. A high-adjusted $R^{2}$ value could be a result of a strong influence from the sex variable.

‡ 'Sugars' include all mono- and disaccharides.

eaten elsewhere. Nevertheless, the correlations we found in the present study were reasonably high and it seems that even though teenagers are striving to gain independence, the family - in this case, the mother - still has a great influence on their food habits, which has also been seen in other studies $^{(4,13)}$.

Mothers and sons showed no resemblance at all in the intake of macronutrients and total EI, whereas the intake of some food groups had an equally strong correlation as in mothers and daughters. These results emphasise how useful it is to assess different kinds of dietary data and not limit ourselves to only nutrients.

BMI was correlated between mothers and both boys and girls, but lost in boys when adjusting for physical activity. This suggests that shared physical activity habits might be more important than shared eating habits when explaining relationships in BMI between mothers and sons, whereas the diet seems to be the main factor in daughters. The importance of shared physical activity is interesting and needs further attention in another paper.

One limitation of the present study is that the present results and conclusions might be limited to this specific highly educated Swedish population, and it might therefore be hazardous to generalise it to other populations. However, we have shown that boys and girls have different patterns in their resemblance to their mothers. We have also shown that adults and teenagers have different consumption patterns. This is probably true in other populations too, even though the specific food items might be different in another cultural context.

Another limitation, as in all dietary research, is the built-in difficulties and limitations of dietary assessment methods. There is no method for assessing dietary intake available entirely free of bias. However, the questionnaire used in the present study has been proven to be reasonably valid in previous studies ${ }^{(21,22)}$. Nevertheless, as in all other studies of the diet, the results have to be carefully reviewed in the light of possible misreporting.

The prevalence of over- and under-reporters of total EI in this population has been estimated. A greater problem is the possible selective misreporting, something that is impossible to estimate. However, we have assumed that the pattern of how mothers and children misreport their food intake is quite similar. Generally, foods considered unhealthy are more often under-reported ${ }^{(36,37)}$ and foods considered healthy are more often over-reported ${ }^{(38)}$. It is likely that mothers and their teenaged children have the same opinions of these foods, the same foods being under- and over-reported, and therefore the results of the correlations are not heavily burdened by selective misreporting.

Information on the role of parents will help us in understanding how to involve them in improving the diet of their children. Our expectation was that foods eaten at breakfast and dinner would be more correlated between parents and children than snack foods, since we know that these meals most often are consumed at home ${ }^{(39)}$. Instead, the significant results included mainly snack foods, such as salty snacks and cakes, in both boys and girls, whereas milk and cooked meals had no or low correlation. These results could be of help when designing prevention strategies aimed at the parents. If we can convince parents to decrease their intake of snack foods, it might have an impact on the snack food consumption of their children, and it is probably better to intervene as early as possible.

\section{Acknowledgements}

Sources of support: the data collection phase of the present study was funded by the European Commission, Quality of Life and Management of Living Resources, Key action 1 'Food, nutrition and health' programme as part of the project entitled 'Dietary and genetic influences on susceptibility or resistance to weight gain on a high-fat diet' (QLK1-2000$00515)$. There is no conflict of interest.

\section{References}

1. Neovius M, Teixeira-Pinto A \& Rasmussen F (2008) Shift in the composition of obesity in young adult men in Sweden over a third of a century. Int J Obes (Lond) 32, 832-836.

2. Wang Y \& Lobstein T (2006) Worldwide trends in childhood overweight and obesity. Int J Pediatr Obes 1, 11-25.

3. Wardle J (1995) Parental influences on children's diets. Proc Nutr Soc 54, 747-758.

4. Guidetti M \& Cavazza N (2008) Structure of the relationship between parents' and children's food preferences and avoidances: an explorative study. Appetite 50, 83-90.

5. Mirmiran P, Mirbolooki M \& Azizi F (2002) Familial clustering of obesity and the role of nutrition: Tehran lipids and glucose study. Int J Obes 26, 1617-1622.

6. Nguyen VT, Larson DE, Johnson RK, et al. (1996) Fat intake and adiposity in children of lean and obese parents. Am J Clin Nutr 63, 507-513.

7. Krahnstoever Davison K, Francis LA \& Birch LL (2005) Reexamining obesigenic families: parents' obesity-related behaviors predict girls' change in BMI. Obes Res 13, 1980-1990.

8. Galloway AT, Fiorito L, Lee Y, et al. (2005) Parental pressure, dietary patterns, and weight status among girls who are 'picky eaters'. J Am Diet Assoc 105, 541-548. 
9. Taveras EM, Rifas-Shiman SL, Berkey CS, et al. (2005) Family dinner and adolescent overweight. Obes Res 13, 900-906.

10. Sen B (2006) Frequency of family dinner and adolescent body weight status: evidence from the national longitudinal survey of youth, 1997. Obesity (Silver Spring) 14, 2266-2276.

11. Elfhag K \& Linne Y (2005) Gender differences in associations of eating pathology between mothers and their adolescent offspring. Obes Res 13, 1070-1076.

12. Blissett J, Meyer C \& Haycraft E (2006) Maternal and paternal controlling feeding practices with male and female children. Appetite 47, 212-219.

13. Feunekes GI, Stafleu A, de Graaf C, et al. (1997) Family resemblance in fat intake in The Netherlands. Eur J Clin Nutr 51, 793-799.

14. Gillman MW, Rifas-Shiman SL, Frazier AL, et al. (2000) Family dinner and diet quality among older children and adolescents. Arch Fam Med 9, 235-240.

15. Lau RR, Quadrel MJ \& Hartman KA (1990) Development and change of young adults' preventive health beliefs and behavior: influence from parents and peers. J Health Soc Behav 31, 240-259.

16. Vauthier J, Lluch A, Lecomte E, et al. (1996) Family resemblence in energy and macronutrient intakes: the Stanislas Family Study. Int J Epidemiol 25, 1030-1037.

17. Oliveria SA, Ellison RC, Moore LL, et al. (1992) Parent-child relationships in nutrient intake: the Framingham Children's Study. Am J Clin Nutr 56, 593-598.

18. Vågstrand K (2008) Eating habits among adolescents and their mothers - SWEDES. PhD Thesis, Department of Medicine Huddinge, Karolinska Institutet. http://diss.kib.ki.se/2008/ 978-91-7357-524-9/thesis.pdf

19. Öhlin A \& Rössner S (1996) Factors related to body weight changes during and after pregnancy: the Stockholm Pregnancy and Weight Development Study. Obes Res 4, 271-276.

20. Statistika Centralbyrån - Statistics Sweden (2007) Undersökningar av levnadsvanor - ULF (Examination of living conditions in Sweden) (in Swedish). http://www.scb.se/statistik/LE/LE101/ 2007A01T/UT3_07VF.xls (accessed December 2009).

21. Lindroos AK, Lissner L \& Sjöström L (1993) Validity and reproducibility of a self-administered dietary questionnaire in obese and non-obese subjects. Eur J Clin Nutr 47, 461-481.

22. Lindroos AK, Lissner L \& Sjöström L (1995) A dietary questionnaire for obese people - development and application. In 6th European Congress on Obesity May 31-June 3, Copenhagen. 19, Suppl. 2, 75 (abstract).

23. Livsmedelsverket (1986) Food Composition Tables, 2nd ed. Stockholm: Liber Tryck AB.

24. Ekelund U, Neovius M, Linne Y, et al. (2006) The criterion validity of a last 7-day physical activity questionnaire (SAPAQ) for use in adolescents with a wide variation in body fat: the Stockholm Weight Development Study. Int J Obes 30, 1019-1021.
25. Craig C, Marshall A, Sjostrom M, et al. (2003) International physical activity questionnaire: 12-country reliability and validity. Med Sci Sports Exerc 35, 1381-1395.

26. Schofield WN (1985) Predicting basal metabolic rate, new standards and review of previous work. Hum Nutr Clin Nutr 39C, 5-41.

27. Vagstrand K, Lindroos AK \& Linne Y (2009) Characteristics of high and low energy reporting teenagers and their relationship to low energy reporting mothers. Publ Health Nutr 12, 188-196.

28. Kipnis V, Freedman LS, Brown CC, et al. (1997) Effect of measurement error on energy-adjustment models in nutritional epidemiology. Am J Epidemiol 146, 842-855.

29. Willett W (1998) Nutritional epidemiology. In Monographs in Epidemiology and Biostatistics. vol. 30, New York: Oxford university press. pp. $288-291$.

30. van der Horst K, Oenema A, Ferreira I, et al. (2007) A systematic review of environmental correlates of obesity-related dietary behaviors in youth. Health Educ Res 22, 203-226.

31. Westenhoefer J (2005) Age and gender dependent profile of food choice. Forum Nutr 57, 44-51.

32. Crawley HF (1993) The energy, nutrient and food intakes of teenagers aged 16-17 years in Britain. Br J Nutr 70, 15-26.

33. Samuelson G, Bratteby L-E, Enghardt H, et al. (1996) Food habits and energy and nutrient intake in Swedish adolescents approaching the year 2000. Acta Paediatr 85, 1392.

34. Becker W \& Pearson M (1997) Kostvanor och näringsintag $i$ Sverige (Food habits and nutritional intake in Sweden). Uppsala: National Food Administration (Livsmedelsverket) (In Swedish). pp. 33-109. http://www.slv.se/upload/dokument/ rapporter/kostundersokningar/riksmat.pdf

35. Vagstrand K, Barkeling B, Forslund HB, et al. (2007) Eating habits in relation to body fatness and gender in adolescentsresults from the 'SWEDES' study. Eur J Clin Nutr 61, 517-525.

36. Heitmann BL \& Lissner L (1995) Dietary underreporting by obese individuals - is it specific or non-specific? BMJ 311, 986-989.

37. Goris A, Westerterp-Plantenga M \& Westerterp K (2000) Undereating and underrecording of habitual food intake in obese men: selective underreporting of fat intake. Am J Clin Nutr 71, 130-134.

38. Mela DJ \& Aaron JI (1997) Honest but invalid: what subjects say about recording their food intake. $J$ Am Diet Assoc 97, 791-793.

39. Woodruff SJ \& Hanning RM (2008) A review of family meal influence on adolescents' dietary intake. Can J Diet Pract Res 69, $14-22$

40. Cole TJ, Bellizzi MC, Flegal KM, et al. (2000) Establishing a standard definition for child overweight and obesity worldwide: international survey. BMJ 320, 1240-1243. 